\title{
Alphavirus Replication: The Role of Cardiac Glycosides and Ion Concentration in Host Cells
}

\author{
Kauê F. C. Souza-Souza, ${ }^{1}$ Cassiano F. Gonçalves-de-Albuquerque $\mathbb{D}^{2,3}$ \\ Cláudio Cirne-Santos, ${ }^{1}$ Izabel C. N. P. Paixão, ${ }^{1}$ and Patrícia Burth ${ }^{1}{ }^{1}$ \\ ${ }^{1}$ Departamento de Biologia Celular e Molecular, Instituto de Biologia, Universidade Federal Fluminense, Niterói, \\ RJ CEP 24020-141, Brazil \\ ${ }^{2}$ Departamento de Bioquímica, Universidade Federal do Estado do Rio de Janeiro, Rio de Janeiro, RJ CEP 20211-010, Brazil \\ ${ }^{3}$ Laboratório de Imunofarmacologia, Instituto Oswaldo Cruz, FIOCRUZ, Rio de Janeiro, RJ CEP 21040-900, Brazil
}

Correspondence should be addressed to Patrícia Burth; patburth@gmail.com

Received 20 December 2019; Revised 31 March 2020; Accepted 15 April 2020; Published 9 May 2020

Academic Editor: Yanjin Zhang

Copyright (C) 2020 Kauê F. C. Souza-Souza et al. This is an open access article distributed under the Creative Commons Attribution License, which permits unrestricted use, distribution, and reproduction in any medium, provided the original work is properly cited.

\begin{abstract}
Alphaviruses are arthropod-borne viruses that can cause fever, rash, arthralgias, and encephalitis. The mosquito species Aedes aegypti and Aedes albopictus are the most frequent transmitters of alphaviruses. There are no effective vaccines or specific antivirals available for the treatment of alphavirus-related infections. Interestingly, changes in ion concentration in host cells have been characterized as critical regulators of the alphavirus life cycle, including fusion with the host cell, glycoprotein trafficking, genome translation, and viral budding. Cardiac glycosides, which are classical inhibitors of the $\mathrm{Na}^{+} \mathrm{K}^{+} \mathrm{ATPase}$ (NKA), can inhibit alphavirus replication although their mechanisms of action are poorly understood. Nonetheless, results from multiple studies suggest that inhibition of NKA may be a suitable strategy for the development of alphavirus-specific antiviral treatments. This review is aimed at exploring the role of changes in ion concentration during alphavirus replication and at considering the possibility of NKA as a potential therapeutic target for antiviral drugs.
\end{abstract}

\section{Introduction}

Viruses of the genus Alphavirus genus are a subset of the family Togaviridae [1]. Among the 31 virus species that are included in this family [2], only salmon pancreatic disease virus and Southern elephant seal virus are not arthropod-borne [3]. The Alphavirus genus includes Eastern equine encephalitis virus, Venezuelan equine encephalitis virus, and Western equine encephalitis virus, which are pathogens that can infect mammalian species and cause encephalitis [4]. Other members of this genus include Chikungunya virus (CHIKV), O'nyong-nyong virus, Ross River virus, Semliki Forest virus, Mayaro, and Sindbis virus; infections with these viruses are associated with fever, rash, and arthralgias [5]. Alphavirus virions are small, regularly-shaped spherical particles with positive-sense single-stranded RNA genome covered by an icosahedral capsid (nucleocapsid) that contains glycoprotein components in an icosahedral lattice [6]. The capsid consists of two icosahedral shells that are formed from a host-derived membrane bilayer [7] located between the inner and outer shells and penetrated by transmembrane domain anchors of E1 and E2 proteins [8]. The E2 domain is essential for maintaining interactions with E1 and the capsid protein and is a critical target of neutralizing antibodies [9].

The primary vectors responsible for alphavirus infections are the mosquitos Aedes aegypti and Aedes albopictus [10]. Uncontrolled urbanization favors vector expansion, boosts the emergence of viruses, and interferes with infection control measures [11]. Currently, there are no effective vaccines or treatments for disease caused by these pathogens [12]. 
An alternative approach might include antiviral drugs that target critical host proteins, similar to what has been done for human immunodeficiency virus $[13,14]$; however, at this time, the role of host proteins in the virus lifecycle has not been studied to a sufficient degree $[7,15]$.

Decades ago, several reports documented changes in ion concentrations within host cells that were linked to viral replication [16]. For example, increasing the $\mathrm{NaCl}$ concentration in tissue culture medium directly inhibits maturation and release of the Sindbis virus, Semliki Forest, and vesicular Stomatitis virus [17]. By contrast, elevated $\mathrm{NaCl}$ concentrations were also associated with increased transcription efficiency of Sindbis virus messenger RNA (mRNA) [18]. The significance of the $\mathrm{Na}^{+}$ion concentration and its impact on reducing viral yield was also considered in experiments focused on Chikungunya virus (CHIKV) infection in human osteosarcoma cells. Interestingly, treatment of human cells with digoxin or the related cardiac glycoside, ouabain, resulted in a dosedependent decrease in the efficacy of CHIKV infection. Other alphaviruses, including Ross River virus and Sindbis virus, as well as mammalian reovirus and vesicular stomatitis virus, are sensitive to the antiviral activity of digoxin [19].

In 2015, Fields and Kielian documented the critical role of $\mathrm{H}^{+}$ion concentration in the mechanism underlying alphavirus fusion [20]. Increased $\mathrm{H}^{+}$ion concentration was also required for nucleocapsid disassembly and translocation of the viral genome [21]. Therefore, a more in-depth analysis of proteins that regulate the ion flow within host cells, notably the aforementioned $\mathrm{Na}^{+} \mathrm{K}^{+}$ATPase (NKA), may reveal new targets and therapeutic strategies for the treatment of alphavirus infections.

\section{2. $\mathrm{Na}^{+} \mathrm{K}^{+}$ATPase (NKA)}

NKA is a transmembrane enzyme. Its mechanism of action was explored many years ago and includes its capacity for ion exchange, specifically the transfer of three $\mathrm{Na}^{+}$ions to the extracellular space in exchange for two $\mathrm{K}^{+}$ions imported into the cell cytosol, accompanied by the hydrolysis of ATP. NKA activity is crucial for maintaining the electrochemical gradient and cellular osmolarity [22]. Appropriate NKA function is critical factor for renal filtration, reabsorption of amino acids and glucose, and regulation of electrolyte and $\mathrm{pH}$ levels in the blood [23] as well as sperm motility and generation of neuronal action potentials [24]. NKA includes three submits known as $\alpha, \beta$, and $\gamma$ [24]. The $\alpha$ catalytic subunit contains binding sites for $\mathrm{Na}^{+}, \mathrm{K}^{+}$, and $\mathrm{Mg}^{++}$ions, ATP, and cardiac glycoside inhibitors [25]. The $\beta$ subunit stabilizes and guides $\alpha$ subunit within the membrane and controls its affinity for $\mathrm{K}^{+}$ions and cardiac glycoside inhibitors [26]. The $\gamma$ subunit modulates the affinity for $\mathrm{Na}^{+}$and $\mathrm{K}^{+}$ions [24]. NKA can also transduce signals from the extracellular space [27]. This complex, multisubunit function may have been acquired during the evolution by incorporation of many domains that interact with specific ligands and intracellular proteins, similar to what has been observed for the protooncogene tyrosine-protein kinase $\mathrm{Src}(\mathrm{Src})$, protein kinase C (PKC), phosphoinositide 3-kinase (PI3K), protein kinase A (PKA), extracellular signal-regulated kinase (ERK), and the caveolins [28-30]. This function, however, seems to be restricted to caveolae and unrelated to the $\mathrm{Na}^{+} \mathrm{K}^{+}$exchange function $[31,32]$.

Cardiac glycosides are classical inhibitors of the NKA [30]. They are used in the treatment of patients with heart failure because of their potent inotropic effect $[33,34]$. Cardiac glycosides, such as ouabain and digoxin, disrupt the flow of the $\mathrm{Na}^{+}$and $\mathrm{K}^{+}$ions, resulting in a significant change in the cellular ion gradient. Inhibition of NKA generates an increase in intracellular $\mathrm{Na}^{+}$concentration and activates $\mathrm{Na}^{+} / \mathrm{Ca}^{++}$exchanger; this results in an increase in intracellular $\mathrm{Ca}^{++}$which promotes cardiac contractility $[33,35]$. Cardiac glycosides also trigger signal transduction and can activate intracellular pathways through NKA at low concentrations $[30,36]$.

The cardiac glycosides have also been linked to antiviral activity [37-40]. For example, adenovirus relies on the host pre-RNA splicing machinery for genome expression; as such, this virus will be vulnerable to digoxin and digitoxin, which can modulate RNA splicing. The yields of human adenovirus are reduced by at least 2 to 3 logs by these drugs. Cardiac glycosides can disrupt virus genome replication and transcription but do not promote target cell death [41]. Furthermore, Cai et al. [42] reported that cardiac glycosides inhibit cytomegalovirus replication and that the combination of ganciclovir (GCV) and cardiac glycosides (digoxin, digitoxin, and ouabain) resulted in additive antiviral effects. Despite these impressive effects, there are comparatively few studies that directly address the role of cardiac glycosides as putative antiviral agents [43].

\section{Influence of the Ion Change during Attachment, Fusion, and Nucleocapsid Disassembly}

Alphavirus infection is initiated by binding to the surface cell host receptor [44] which results in fusion and internalization [45]; an alternate pathway for cell penetration includes direct transfer of virus RNA through pores formed in the plasma membrane during infection [46-48]. As part of the fusion process, the E2 envelope protein binds to cell receptors [49], and the E1 protein acts to promote viral envelope fusion with the host endosomal membrane [50]. The E3 protein protects against premature activation of E1 and facilitates pE2/E1 heterodimerization [51]. Interestingly, the viral particles inhibit NKA during attachment to the host cell membrane [52]; Carrasco [16] reported that infection with Semliki Forest altered ion gradient at the host cell membrane.

During virus fusion with the host cell membrane, the high $\mathrm{H}^{+}$concentration inside the endosome promotes capsid protein degradation [47]. The degradation occurs because of high $\mathrm{H}^{+}$concentrations which result in E1 protein permeability to $\mathrm{Na}^{+}, \mathrm{K}^{+}$, and $\mathrm{Ca}^{+}$ions which allows endosomal protons to flow into the cytoplasm via exchange $\mathrm{K}^{+}$ions. The high $\mathrm{H}^{+}$ion concentration within the endosomes promotes nucleocapsid disassembly and translocation of the viral genome [21]. The cellular 60S ribosome efficiently removes the nucleocapsid proteins and exposes the viral RNA [53, 
54]. An alternate mechanism for nucleocapsid disassembly involves pore formation by the virus E1 protein which serves to direct protons into the viral particle, thereby facilitating the uncoating viral RNA [55] via the actions of ion channels that promote $\mathrm{Na}^{+} / \mathrm{Cl}^{+}$and $\mathrm{Na}^{+} / \mathrm{K}^{+}$exchange by the viral protein $6 \mathrm{k}[56]$.

\section{Role of Ion Change in Viral Genome Replication}

Alphavirus genome is a single strand of positive sense RNA; coding segments at the $5^{\prime}$ end of the genome are those related to genomic replication and mRNA synthesis, and coding sequences at the $3^{\prime}$ end are those that encode virus structural proteins [6, 57]. Nonstructural proteins, including nsP1 (methyltransferase), nsP2 (helicase), nsP3 (an accessory in the synthesis of the negative RNA strand), and nsP4 (RNA polymerase), are generated by the sequential cleavage of the nonstructural polyprotein P1234 [58, 59]; these proteins are components of the replication complex within cytopathic vacuoles [60]. The functional arrangement within the replicase complex is not clearly understood [15]. The structural proteins, including C (capsid protein), E1 (glycoprotein), pE2 (which is cleaved in the Golgi to generate E2 and E3 glycoproteins), and a small peptide termed $6 \mathrm{~K}$, are all parts of a cation-selective ion channel $[56,61]$ and are translated from a subgenomic mRNAs as a polyprotein (p130) on the polysomes [62]. C protein, the first to be synthesized, is responsible for carrying out self-cleavage and for releasing capsid protein into the cytoplasm [62]. In the cytoplasm, the C protein includes a signal sequence directing it to the endoplasmic reticulum, where it undergoes further processing to become a viral capsid protein [62].

The nonstructural proteins have been identified as attractive targets for antiviral therapeutics [63, 64]. Digoxin induces mutations in non-structural proteins, including nsP4, in CHIKV-infected cells, resulting in disruption of RNA synthesis and/or the replication complex that is essential for alphavirus replication [19].

Bafilomycin A1 (BAF) is a specific inhibitor of the vacuolar-ATPase (V-ATPase) which is responsible for the acidification of endosomes. BAF has been used to inhibit alphavirus infection, with the assumption that the acidification of endosomes by the V-ATPase was required for penetration, endocytosis, and intracellular vesicle transport. A functional V-ATPase is required for efficient alphavirus RNA synthesis and maturation [65].

Increasing $\mathrm{NaCl}$ concentration in the culture medium of epithelial osteosarcoma cells treated with digoxin $(0.25 \mu \mathrm{M})$ resulted in significant inhibition of CHIKV yield; increasing the $\mathrm{KCl}$ concentration had the opposite effect [19]. Increases in the intracellular concentrations of $\mathrm{Na}^{+}$in cells infected by Sindbis virus resulted in inhibited protein synthesis and increases in the levels of untranslated mRNA in the host cells; these studies suggest a crucial role for $\mathrm{Na}^{+}$with respect to virus replication [66]. Taken together, these results suggest that digoxin actions on viral replication via its ability to inhibit NKA [19].

\section{Influence of the Ion Change during Morphogenesis and Viral Budding}

Viral morphogenesis begins just after the replication process. The newly synthesized capsid proteins are transferred directly to the nucleocapsid or released in association with $80 \mathrm{~S}$ monosomes [67]. The region that includes amino acids 81 to 113 of the Sindbis virus capsid protein is responsible for encapsidation of the viral RNA and for the accumulation of nucleocapsid proteins in the cytoplasm of infected cells [68].

The assembly of viral structural proteins at the plasma membrane prior to the release of viral particles is linked to the inhibition of NKA [69]. The entry of alphaviruses into the plasma membrane converts proteins from the viral surface into an ion-permeable pore. Available evidence suggests that the alphavirus E1 protein probably forms these pores [53]. The $6 \mathrm{k}$ protein is a small polypeptide that is rich in cysteines that is typically associated with p62-E1 heterodimers (p62 is the precursor of E3 and E2) [70] and interacts with fatty acids inserted on a lipid bilayer via a hydrophobic sequence [71]. The activities of $6 \mathrm{k}$ are crucial for the successful release of virions from host cells [72]. In addition to its role in creating an ion channel that is selective for $\mathrm{Na}^{+}, \mathrm{K}^{+}$, $\mathrm{Ca}^{++}$, and $\mathrm{Cl}^{-}$ions, the $6 \mathrm{k}$ protein participates in glycoprotein trafficking [73] and can induce caspase-dependent programmed cell death [74]. The $6 \mathrm{k}$ protein functions as an ion channel during virus budding $[56,75]$.

\section{6. $\mathrm{Na}^{+} \mathrm{K}^{+}$ATPase as a Potential Drug Target}

Cardiac glycosides have antiviral activity in the setting of alphavirus infection [19, 76]. Ganesan et al. [77] showed that ouabain exerted a specific inhibitory effect on Sindbis virus RNA synthesis in Aedes albopictus cell lines that were resistant to the gene silencer, bromodeoxyuridine [77]. The antiviral activity of cardiac glycoside includes interference prior to virus attachment, as has been shown in human osteosarcoma cells (U-2 OS) infected with CHIKV virus, River virus, Sindbis virus, and vesicular stomatitis virus [19]. Membrane fractions obtained from Sindbis virus-infected chick embryo cells also were also found to be ouabain-sensitive [78], as were other alphavirus pathogens [41, 79-83].

As the NKA is the sole target of cardiac glycosides, the aforementioned results strongly suggest a link between the antiviral effect of these agents and NKA function [19]. The cardiac glycoside mechanism of antiviral action, however, remains unclear. We suggest two possible hypotheses: first, cardiac glycosides have a clear impact on intracellular ion concentrations, and second, they trigger intracellular signaling cascades that can impair virus replication. Some data suggest that Src activation by cardiac glycosides can trigger MAPK (extracellular signal-regulated kinase (ERK) 1/2) signaling through the Raf-MEK cascade, resulting in the inhibition of viral gene expression; however, these data were generated in HIV-infected cells treated with a cardiotonic steroid [84]. 


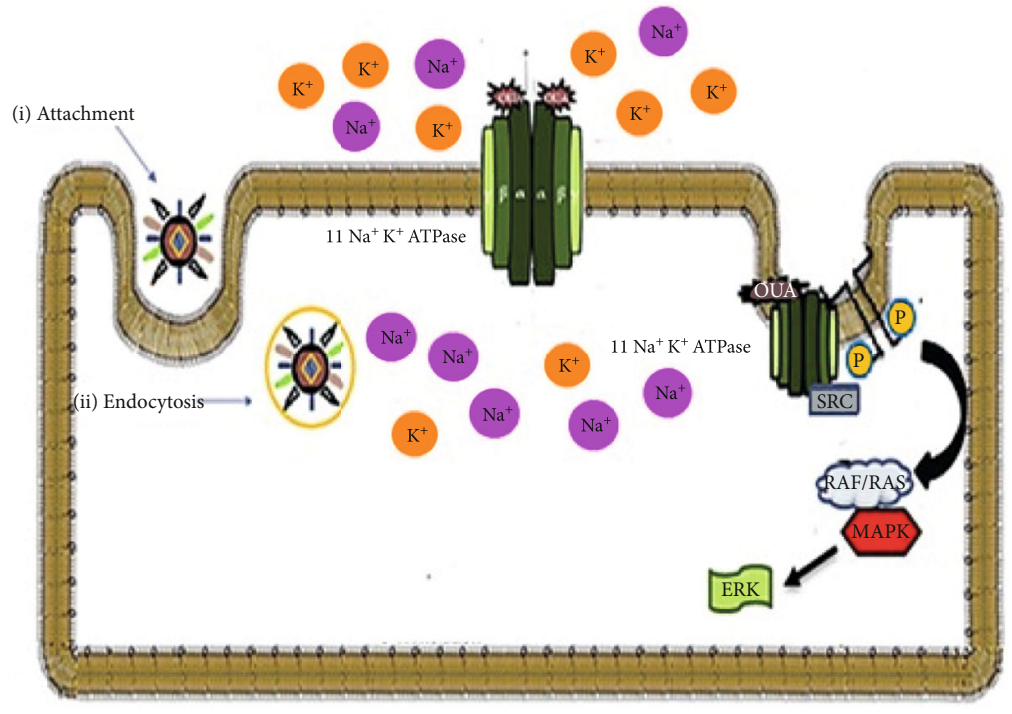

(a)

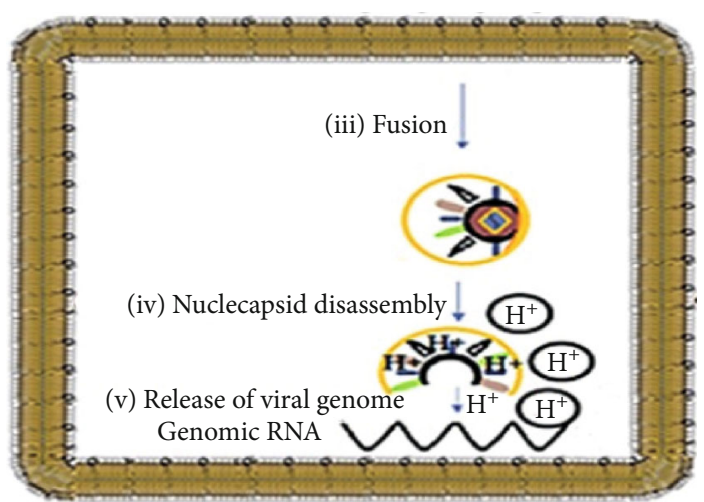

(b)

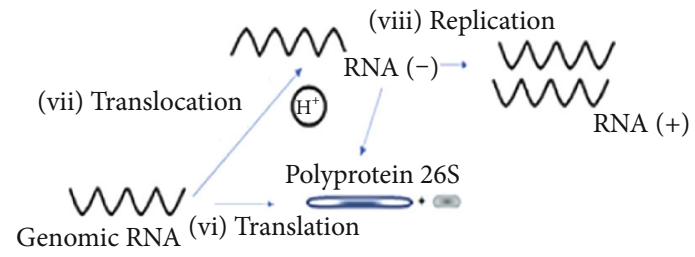

(c)

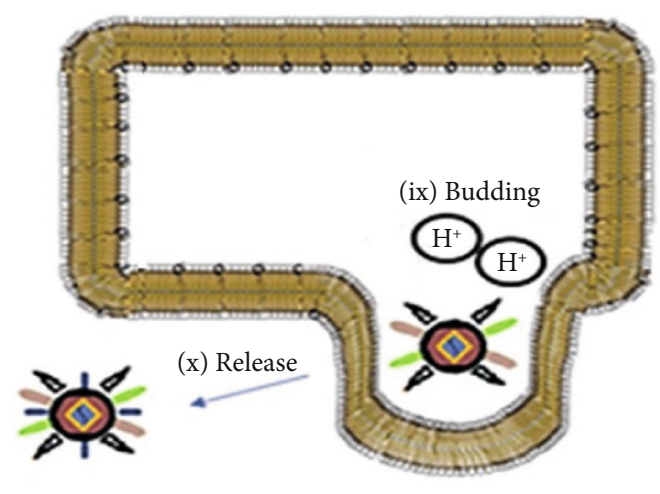

(d)

FIGURE 1: The role of ion concentration during alphavirus replication. Alphavirus infection is initiated by attachment (a-i) and binding to the host cell surface receptor and the virus is then internalized by endocytosis (a-ii). During virus fusion with the host cell membrane (a-iii), a high $\mathrm{H}^{+}$concentration inside the endosome promotes degradation of the capsid protein, nucleocapsid disassembly (b-iv), and release of the viral genome into the cytoplasm (b-v). The genomic RNA is the template for protein translation from both whole genomic and subgenomic (26S) RNA (c-vi) and also the transcription of RNA (+) via a RNA (-) template intermediary (c-vii). The viral genome is replicated (c-iii) and incorporated into a new viral particle. The last phase is the virus budding at the host cell membrane in the presence of elevated $\mathrm{H}^{+}$ion concentration (d-ix) followed by virion release (d-x). The inhibition of $\mathrm{Na}^{+} \mathrm{K}^{+}$ATPase by the cardiac glycoside, ouabain (OUA) (a-xi), results in a change cell osmotic concentration and (c-vi) interrupting synthesis polyprotein through ion change and/or by cell signaling pathways that limit virus replication.

Overall, cardiac glycosides create an unfavorable environment for virus replication [36]. The possibility that the cardiac glycoside/NKA axis could be targeted by novel antiviral therapeutics merits further consideration.

\section{Conclusions}

The alphavirus replication cycle is profoundly affected by changes in host intracellular ion concentrations (Figure 1). Changes in the concentration of the $\mathrm{Na}^{+}$and $\mathrm{K}^{+}$ions interfere in the gene expression, virus yield, and can inhibit intracellular viral protein synthesis. The inhibition of CHIKV replication by the cardiac glycoside, digoxin, can be altered by increasing the extracellular potassium concentration, suggesting that antagonism of sodium-potassium ATPase is a critical mediator of the antiviral effect. The antiviral effect may be directly associated with NKA inhibition [19,37], suggesting that this enzyme may be a target for novel antiviral therapeutics. We believe that further studies will unveil the precise mechanisms of action of antiviral drugs targeting NKA and will boost further research in the field.

\section{Conflicts of Interest}

The authors declare that there are no conflicts of interest.

\section{Acknowledgments}

This research was partially supported by Post-graduation in Science and Biotechnology from Universidade Federal Fluminense and financial support from Universidade Federal do Estado do Rio de Janeiro, CAPES, FAPERJ, and CNPq. 


\section{References}

[1] B. S. Schnierle, "Cellular attachment and entry factors for Chikungunya virus," Viruses, vol. 11, no. 11, article v11111078, p. $1078,2019$.

[2] E. J. Lefkowitz, D. M. Dempsey, R. C. Hendrickson, R. J. Orton, S. G. Siddell, and D. B. Smith, "Virus taxonomy: the database of the international committee on taxonomy of viruses (ICTV)," Nucleic Acids Research, vol. 46, no. D1, pp. D708D717, 2018.

[3] D. J. Gubler, "The global emergence/resurgence of arboviral diseases as public health problems," Archives of Medical Research, vol. 33, no. 4, pp. 330-342, 2002.

[4] N. Garmashova, R. Gorchakov, E. Volkova, S. Paessler, E. Frolova, and I. Frolov, "The Old World and New World alphaviruses use different virus-specific proteins for induction of transcriptional shutoff," Journal of Virology, vol. 81, no. 5, pp. 2472-2484, 2007.

[5] A. Suhrbier, M. C. Jaffar-Bandjee, and P. Gasque, "Arthritogenic alphaviruses-an overview," Nature Reviews Rheumatology, vol. 8, no. 7, pp. 420-429, 2012.

[6] R. Zhang, C. F. Hryc, Y. Cong et al., "4.4 Å cryo-EM structure of an enveloped alphavirus Venezuelan equine encephalitis virus," The EMBO Journal, vol. 30, no. 18, pp. 3854-3863, 2011.

[7] J. Jose, J. E. Snyder, and R. J. Kuhn, "A structural and functional perspective of alphavirus replication and assembly," Future Microbiology, vol. 4, no. 7, pp. 837-856, 2009.

[8] J. E. Voss, M. C. Vaney, S. Duquerroy et al., "Glycoprotein organization of Chikungunya virus particles revealed by $\mathrm{X}$ ray crystallography," Nature, vol. 468, no. 7324, pp. 709-712, 2010.

[9] J. Weger-Lucarelli, M. T. Aliota, A. Kamlangdee, and J. E. Osorio, "Identifying the role of E2 domains on alphavirus neutralization and protective immune responses," PLOS Neglected Tropical Diseases, vol. 9, no. 10, article e0004163, 2015.

[10] A. Higuera and J. D. Ramirez, "Molecular epidemiology of dengue, yellow fever, Zika and Chikungunya arboviruses: an update," Acta Tropica, vol. 190, pp. 99-111, 2019.

[11] L. W. Olivia, V. Obanda, G. Bucht et al., "Global emergence of alphaviruses that cause arthritis in humans," Infection Ecology \& Epidemiology, vol. 5, no. 1, article 29853, 2015.

[12] A. Mendes and R. Kuhn, "Alphavirus nucleocapsid packaging and assembly," Viruses, vol. 10, no. 3, article v10030138, p. 138, 2018.

[13] L. Fantuzzi, M. Tagliamonte, M. C. Gauzzi, and L. Lopalco, "Dual CCR5/CCR2 targeting: opportunities for the cure of complex disorders," Cellular and Molecular Life Sciences, vol. 76, no. 24, pp. 4869-4886, 2019.

[14] J. Yasuhara-Bell and Y. Lu, "Marine compounds and their antiviral activities," Antiviral Research, vol. 86, no. 3, pp. 231-240, 2010.

[15] J. C. Rupp, K. J. Sokoloski, N. N. Gebhart, and R. W. Hardy, "Alphavirus RNA synthesis and non-structural protein functions," The Journal of General Virology, vol. 96, no. 9, pp. 2483-2500, 2015.

[16] L. Carrasco, "The inhibition of cell functions after viral infection. A proposed general mechanism," FEBS Letters, vol. 76, no. 1, pp. 11-15, 1977.

[17] E. G. Strauss, E. M. Lenches, and M. A. Stamreich-Martin, "Growth and release of several alphaviruses in chick and
BHK cells," Journal of General Virology, vol. 49, no. 2, pp. 297-307, 1980.

[18] J. R. Bell, M. W. Hunkapiller, L. E. Hood, and J. H. Strauss, "Amino-terminal sequence analysis of the structural proteins of Sindbis virus," Proceedings of the National Academy of Sciences, vol. 75, no. 6, pp. 2722-2726, 1978.

[19] A. W. Ashbrook, A. J. Lentscher, P. F. Zamora et al., "Antagonism of the sodium-potassium ATPase impairs Chikungunya virus infection," mBio, vol. 7, no. 3, 2016.

[20] W. Fields and M. Kielian, "Interactions involved in $\mathrm{pH}$ protection of the alphavirus fusion protein," Virology, vol. 486, pp. 173-179, 2015.

[21] D. L. Gibbons, I. Erk, B. Reilly et al., "Visualization of the target-membrane-inserted fusion protein of Semliki Forest virus by combined electron microscopy and crystallography," Cell, vol. 114, no. 5, pp. 573-583, 2003.

[22] A. G. Saez, E. Lozano, and A. Zaldivar-Riveron, "Evolutionary history of $\mathrm{Na}, \mathrm{K}-\mathrm{ATPases}$ and their osmoregulatory role," Genetica, vol. 136, no. 3, article 9356, pp. 479-490, 2009.

[23] G. Sweeney, W. Niu, V. A. Canfield, R. Levenson, and A. Klip, "Insulin increases plasma membrane content and reduces phosphorylation of $\mathrm{Na}^{+}-\mathrm{K}^{+}$pump $\alpha_{1}$-subunit in HEK-293 cells," American Journal of Physiology-Cell Physiology, vol. 281, no. 6, pp. C1797-C1803, 2001.

[24] M. V. Clausen, F. Hilbers, and H. Poulsen, "The structure and function of the Na,K-ATPase isoforms in health and disease," Frontiers in Physiology, vol. 8, p. 371, 2017.

[25] J. P. Morth, H. Poulsen, M. S. Toustrup-Jensen et al., "The structure of the $\mathrm{Na}^{+}, \mathrm{K}^{+}$-ATPase and mapping of isoform differences and disease-related mutations," Philosophical Transactions of the Royal Society B: Biological Sciences, vol. 364, no. 1514, pp. 217-227, 2009.

[26] J. B. Lingrel, "The physiological significance of the cardiotonic steroid/ouabain- binding site of the Na,K-ATPase," Annual Review of Physiology, vol. 72, no. 1, pp. 395-412, 2010.

[27] X. Cui and Z. Xie, "Protein interaction and Na/K-ATPasemediated signal transduction," Molecules, vol. 22, no. 6, p. 990, 2017.

[28] A. Aperia, E. E. Akkuratov, J. M. Fontana, and H. Brismar, " $\mathrm{Na}^{+}-\mathrm{K}^{+}$-ATPase, a new class of plasma membrane receptors," American Journal of Physiology. Cell Physiology, vol. 310, no. 7, pp. C491-C495, 2016.

[29] Y. Bai, J. Wu, D. Li et al., "Differential roles of caveolin-1 in ouabain-induced $\mathrm{Na}^{+} / \mathrm{K}^{+}$-ATPase cardiac signaling and contractility," Physiological Genomics, vol. 48, no. 10, pp. 739748, 2016

[30] M. Diederich, F. Muller, and C. Cerella, "Cardiac glycosides: from molecular targets to immunogenic cell death," Biochemical Pharmacology, vol. 125, pp. 1-11, 2017.

[31] Z. Xie and T. Cai, "Na+-K+-ATPase-Mediated Signal Transduction: From Protein Interaction to Cellular Function," Molecular Interventions, vol. 3, no. 3, pp. 157-168, 2003.

[32] L. E. Quintas, S. V. Pierre, L. Liu, Y. Bai, X. Liu, and Z. J. Xie, "Alterations of $\mathrm{Na}^{+} / \mathrm{K}^{+}$-ATPase function in caveolin-1 knockout cardiac fibroblasts," Journal of Molecular and Cellular Cardiology, vol. 49, no. 3, pp. 525-531, 2010.

[33] R. J. Chen, T. Y. Chung, F. Y. Li, W. H. Yang, T. R. Jinn, and J. T. Tzen, "Steroid-like compounds in Chinese medicines promote blood circulation via inhibition of $\mathrm{Na}^{+} / \mathrm{K}^{+}$-ATPase," Acta Pharmacologica Sinica, vol. 31, no. 6, pp. 696-702, 2010. 
[34] O. J. Ziff and D. Kotecha, "Digoxin: the good and the bad," Trends in Cardiovascular Medicine, vol. 26, no. 7, pp. 585595, 2016.

[35] I. Prassas and E. P. Diamandis, "Novel therapeutic applications of cardiac glycosides," Nature Reviews. Drug Discovery, vol. 7, no. 11, pp. 926-935, 2008.

[36] C. Felippe Goncalves-de-Albuquerque, A. Ribeiro Silva, C. Ignacio da Silva, H. Caire Castro-Faria-Neto, and P. Burth, "Na/K Pump and beyond: $\mathrm{Na} / \mathrm{K}$-ATPase as a modulator of apoptosis and autophagy," Molecules, vol. 22, no. 4, p. 578, 2017.

[37] L. Amarelle and E. Lecuona, "The antiviral effects of Na,KATPase inhibition: a minireview," International Journal of Molecular Sciences, vol. 19, no. 8, p. 2154, 2018.

[38] S. Agostini, H. Ali, C. Vardabasso et al., "Inhibition of Non Canonical HIV-1 Tat Secretion Through the Cellular $\mathrm{Na}^{+}, \mathrm{K}^{+}$-ATPase Blocks HIV-1 Infection," EBioMedicine, vol. 21, pp. 170-181, 2017.

[39] M. J. Norris, M. Malhi, W. Duan et al., "Targeting intracellular ion homeostasis for the control of respiratory syncytial virus," American Journal of Respiratory Cell and Molecular Biology, vol. 59, no. 6, pp. 733-744, 2018.

[40] A. W. Dodson, T. J. Taylor, D. M. Knipe, and D. M. Coen, "Inhibitors of the sodium potassium ATPase that impair herpes simplex virus replication identified via a chemical screening approach," Virology, vol. 366, no. 2, pp. 340-348, 2007.

[41] F. Grosso, P. Stoilov, C. Lingwood, M. Brown, and A. Cochrane, "Suppression of adenovirus replication by cardiotonic steroids," Journal of Virology, vol. 91, no. 3, 2017.

[42] H. Cai, A. Kapoor, R. He et al., "In vitro combination of anticytomegalovirus compounds acting through different targets: role of the slope parameter and insights into mechanisms of action," Antimicrobial Agents and Chemotherapy, vol. 58, no. 2, pp. 986-994, 2014.

[43] C. W. Yang, H. Y. Chang, Y. Z. Lee, H. Y. Hsu, and S. J. Lee, "The cardenolide ouabain suppresses coronaviral replication via augmenting a $\mathrm{Na}^{+} / \mathrm{K}^{+}$-ATPase-dependent PI3K_PDK1 axis signaling," Toxicology and Applied Pharmacology, vol. 356, pp. 90-97, 2018.

[44] M. Kielian, "Structural biology: an alphavirus puzzle solved," Nature, vol. 468, no. 7324, pp. 645-646, 2010.

[45] J. Blazevic, H. Rouha, V. Bradt, F. X. Heinz, and K. Stiasny, "Membrane anchors of the structural Flavivirus proteins and their role in virus assembly," Journal of Virology, vol. 90, no. 14, pp. 6365-6378, 2016.

[46] A. M. Paredes, D. Ferreira, M. Horton et al., "Conformational changes in Sindbis virions resulting from exposure to low $\mathrm{pH}$ and interactions with cells suggest that cell penetration may occur at the cell surface in the absence of membrane fusion," Virology, vol. 324, no. 2, pp. 373-386, 2004.

[47] G. Wengler, A. Koschinski, G. Wengler, and F. Dreyer, "Entry of alphaviruses at the plasma membrane converts the viral surface proteins into an ion-permeable pore that can be detected by electrophysiological analyses of whole-cell membrane currents," Journal of General Virology, vol. 84, no. 1, pp. 173181, 2003.

[48] V. Madan, M. A. Sanz, and L. Carrasco, "Requirement of the vesicular system for membrane permeabilization by Sindbis virus," Virology, vol. 332, no. 1, pp. 307-315, 2005.

[49] C. Weber, E. Berberich, C. von Rhein, L. Henss, E. Hildt, and B. S. Schnierle, "Identification of functional determinants in the Chikungunya virus E2 protein," PLoS Negl Trop Dis, vol. 11, no. 1, p. e0005318, 2017.

[50] M. Kielian, "Mechanisms of virus membrane fusion proteins," Annual Review of Virology, vol. 1, no. 1, pp. 171-189, 2014.

[51] O. Uchime, W. Fields, and M. Kielian, "The Role of E3 in pH Protection during Alphavirus Assembly and Exit," Journal of Virology, vol. 87, no. 18, pp. 10255-10262, 2013.

[52] R. Balanian, "Structural and functional alterations in cultured cells infected with cytocidal viruses," Progress in Medical Virology, vol. 19, pp. 40-83, 1975.

[53] A. Schlegel, J. Schaller, P. Jentsch, and C. Kempf, "Semliki Forest virus core protein fragmentation: its possible role in nucleocapsid disassembly," Bioscience Reports, vol. 13, no. 6, pp. 333-347, 1993.

[54] I. Singh and A. Helenius, "Role of ribosomes in Semliki Forest virus nucleocapsid uncoating," Journal of Virology, vol. 66, no. 12, pp. 7049-7058, 1992.

[55] I. R. Singh, M. Suomalainen, S. Varadarajan, H. Garoff, and A. Helenius, "Multiple mechanisms for the inhibition of entry and uncoating of superinfecting Semliki Forest virus," Virology, vol. 231, no. 1, pp. 59-71, 1997.

[56] J. V. Melton, G. D. Ewart, R. C. Weir, P. G. Board, E. Lee, and P. W. Gage, "Alphavirus 6K proteins form ion channels," Journal of Biological Chemistry, vol. 277, no. 49, pp. 46923-46931, 2002.

[57] P. Liljestrom and H. Garoff, "Internally located cleavable signal sequences direct the formation of Semliki Forest virus membrane proteins from a polyprotein precursor," Journal of Virology, vol. 65, no. 1, pp. 147-154, 1991.

[58] S. Tomar, R. W. Hardy, J. L. Smith, and R. J. Kuhn, "Catalytic core of alphavirus nonstructural protein nsP4 possesses terminal adenylyltransferase activity," Journal of Virology, vol. 80, no. 20, pp. 9962-9969, 2006.

[59] Y. Gao, N. Goonawardane, J. Ward, A. Tuplin, and M. Harris, "Multiple roles of the non-structural protein 3 (nsP3) alphavirus unique domain (AUD) during Chikungunya virus genome replication and transcription," PLOS Pathogens, vol. 15, no. 1, p. e1007239, 2019.

[60] A. Salonen, L. Vasiljeva, A. Merits, J. Magden, E. Jokitalo, and L. Kaariainen, "Properly folded nonstructural polyprotein directs the semliki forest virus replication complex to the endosomal compartment," Journal of Virology, vol. 77, no. 3, pp. 1691-1702, 2003.

[61] F. M. Lum and L. F. Ng, "Cellular and molecular mechanisms of chikungunya pathogenesis," Antiviral Research, vol. 120, pp. 165-174, 2015.

[62] J. H. Strauss and E. G. Strauss, “The alphaviruses: gene expression, replication, and evolution," Microbiological Reviews, vol. 58, no. 3, pp. 491-562, 1994.

[63] M. Solignat, B. Gay, S. Higgs, L. Briant, and C. Devaux, "Replication cycle of chikungunya: a re-emerging arbovirus," Virology, vol. 393, no. 2, pp. 183-197, 2009.

[64] O. Schwartz and M. L. Albert, "Biology and pathogenesis of chikungunya virus," Nature Reviews. Microbiology, vol. 8, no. 7, pp. 491-500, 2010.

[65] S. R. Hunt, R. Hernandez, and D. T. Brown, "Role of the vacuolar-ATPase in Sindbis virus infection," Journal of Virology, vol. 85, no. 3, pp. 1257-1266, 2011.

[66] R. M. Schuchman, R. Vancini, A. Piper et al., "Role of the vacuolar ATPase in the alphavirus replication cycle," Heliyon, vol. 4, no. 7, p. e00701, 2018. 
[67] R. F. Garry, J. M. Bishop, S. Parker, K. Westbrook, G. Lewis, and M. R. Waite, "Na ${ }^{+}$and $\mathrm{K}^{+}$concentrations and the regulation of protein synthesis in Sindbis virus-infected chick cells," Virology, vol. 96, no. 1, pp. 108-120, 1979.

[68] I. Ulmanen, H. Soderlund, and L. Kaariainen, "Role of protein synthesis in the assembly of Semliki forest virus nucleocapsid," Virology, vol. 99, no. 2, pp. 265-276, 1979.

[69] R. Warrier, B. R. Linger, B. L. Golden, and R. J. Kuhn, "Role of sindbis virus capsid protein region II in nucleocapsid core assembly and encapsidation of genomic RNA," Journal of Virology, vol. 82, no. 9, pp. 4461-4470, 2008.

[70] S. Lusa, H. Garoff, and P. Liljeström, "Fate of the $6 \mathrm{~K}$ membrane protein of Semliki Forest virus during virus assembly," Virology, vol. 185, no. 2, pp. 843-846, 1991.

[71] E. T. Ulug, R. F. Garry, M. R. F. Waite, and H. R. Bose Jr., "Alterations in monovalent cation transport in Sindbis virusinfected chick cells," Virology, vol. 132, no. 1, pp. 118-130, 1984.

[72] K. Gaedigk-Nitschko and M. J. Schlesinger, “The Sindbis virus $6 \mathrm{~K}$ protein can be detected in virions and is acylated with fatty acids," Virology, vol. 175, no. 1, pp. 274-281, 1990.

[73] A. Taylor, J. V. Melton, L. J. Herrero et al., "Effects of an inframe deletion of the $6 \mathrm{k}$ gene locus from the genome of Ross River virus," Journal of Virology, vol. 90, no. 8, pp. 41504159, 2016.

[74] M. E. Gonzalez and L. Carrasco, "Viroporins," FEBS Letters, vol. 552, no. 1, pp. 28-34, 2003.

[75] M. A. Sanz, V. Madan, L. Carrasco, and J. L. Nieva, "Interfacial domains in sindbis virus $6 \mathrm{~K}$ protein detection and functional characterization," Journal of Biological Chemistry, vol. 278, no. 3, pp. 2051-2057, 2003.

[76] M. R. Waite, D. T. Brown, and E. R. Pfefferkorn, "Inhibition of Sindbis virus release by media of low ionic strength: an electron microscope study," Journal of Virology, vol. 10, no. 3, pp. 537-544, 1972.

[77] V. Ganesan, B. Duan, and S. Reid, "Chikungunya virus: pathophysiology, mechanism, and modeling," Viruses, vol. 9, no. 12, article v9120368, p. 368, 2017.

[78] S. J. Mento and V. Stollar, "Effect of ouabain on sindbis virus replication in ouabain-sensitive and ouabain-resistant Aedes albopictus cells (Singh)," Virology, vol. 87, no. 1, pp. 58-65, 1978.

[79] E. M. I. N. T. ULUG, R. F. GARRY, and H. R. BOSE, JR, "Inhibition of $\mathrm{Na}^{+} \mathrm{K}^{+}$ATPase Activity in Membranes of Sindbis Virus-Infected Chick Cells," Virology, vol. 216, no. 2, pp. 299-308, 1996.

[80] I. Garcia-Dorival, W. Wu, S. Dowall et al., "Elucidation of the Ebola virus VP24 cellular interactome and disruption of virus biology through targeted inhibition of host-cell protein function," Journal of Proteome Research, vol. 13, no. 11, pp. 5120-5135, 2014.

[81] G. M. Laird, E. E. Eisele, S. A. Rabi, D. Nikolaeva, and R. F. Siliciano, "A novel cell-based high-throughput screen for inhibitors of HIV-1 gene expression and budding identifies the cardiac glycosides," Journal of Antimicrobial Chemotherapy, vol. 69, no. 4, pp. 988-994, 2014.

[82] S. Dowall, K. Bewley, R. Watson et al., "Antiviral screening of multiple compounds against Ebola virus," Viruses, vol. 8, no. 11, article v8110277, p. 277, 2016.
[83] T. Cohen, J. D. Williams, T. J. Opperman, R. Sanchez, N. S. Lurain, and D. Tortorella, "Convallatoxin-induced reduction of methionine import effectively inhibits human cytomegalovirus infection and replication," Journal of Virology, vol. 90, no. 23, pp. 10715-10727, 2016.

[84] R. W. Wong, C. A. Lingwood, M. A. Ostrowski, T. Cabral, and A. Cochrane, "Cardiac glycoside/aglycones inhibit HIV-1 gene expression by a mechanism requiring MEK1/2-ERK1/2 signaling," Sci Rep, vol. 8, no. 1, article 19298, p. 850, 2018. 